\title{
Mouse Model of Colitis-Associated Colorectal Cancer (CAC): Isolation and Characterization of Mucosal- Associated Lymphoid Cells
}

\author{
Llipsy Santiago, Marta Castro, Julián Pardo, and Maykel Arias
}

\begin{abstract}
Colorectal cancer (CRC) is the third most common malignancy worldwide presenting high mortality due to low treatment efficacy. Existing evidence indicates that inflammatory bowel disease (IBD) is associated with a higher risk of developing CRC. Many murine models of inflammation-related colon carcinogenesis (CAC) have been developed to study colon carcinogenesis and novel treatments. A commonly used model involves the combination of a single dose of azoxymethane (AOM), together with three cycles of the inflammatory agent dextran sodium sulfate (DSS) ( 5 days in drinking water followed by a two-week rest). Following this protocol, around $50 \%$ of the animals develop CRCs after 45 days and almost $100 \%$ of animals after 60 days. During CAC development, immune cells, cytokines, and other immune mediators are involved in both tumorigenesis and the elimination of cancer cells during immunotherapy. Thus, the study of mucosal immune responses (including lamina propria mononuclear cells and intraepithelial lymphocytes) is important to understand the role of the immune system during development and therapy in CRC. Single immune cell suspensions from lamina propria and epithelium can be purified combining selective tissue digestion and Percoll gradient centrifugation. Isolated cells can be characterized using flow cytometry by analyzing surface antigens or intracellular cytokines and cytotoxic mediators or employed for further investigations like comparative studies of mRNA expression, cell-proliferation assay, protein analysis, or even functional cytotoxicity assays. The CAC model is useful to study the involvement of immune cells not only during the carcinogenesis process but, in addition, during the treatment with novel immunotherapy protocols.
\end{abstract}

Key words Colitis-associated cancer (CAC), Azoxymethane (AOM), Lamina propria, Monocyte cells (LPMCs), Intraepithelial lymphocytes (IELs), Dextran sodium sulfate (DSS)

\section{Introduction}

Colorectal cancer (CRC) is the third most common malignancy worldwide. This cancer can develop spontaneously or as a late complication of a chronic inflammatory state. The risk of developing CRC involves many genetic and hereditary factors as well as environmental and lifestyle risk factors [1]. However, in all cases, inflammation seems to contribute to the tumorigenesis process.

Alejandro López-Soto and Alicia R. Folgueras (eds.), Cancer Immunosurveillance: Methods and Protocols, Methods in Molecular Biology, vol. 1884, https://doi.org/10.1007/978-1-4939-8885-3_13, @ Springer Science+Business Media, LLC, part of Springer Nature 2019 
The connection between inflammation and tumorigenesis is well established and appears to be mediated by the activity of immune cells. The molecular mechanisms by which inflammation promotes cancer development are still being uncovered and could differ between colitis-associated cancer (CAC) and other forms of colorectal cancer (CRC) [2-5]. Recent works have elucidated the role of immune cells, cytokines, and other immune mediators in all steps of colon tumorigenesis, including initiation, promotion, progression, and metastasis $[4,6,7]$. Paradoxically, some of these immune mediators are also involved in protection against cancer during both immunosurveillance and immunotherapy.

The study of experimental colon carcinogenesis in rodents has a large history. Many murine models of sporadic and inflammationrelated colon carcinogenesis have been developed to study colon carcinogenesis, including genetically engineered mouse models, chemically induced CRC models, and xenotransplants. All these animal models have provided important tools for investigating the development and pathogenesis of CRC and help us understand the sequential of genetic and epigenetic alterations that trigger changes in cell and tumor biology, which is observed in humans [8]. In addition, they are very useful to analyze the efficacy of novel chemotherapy and immunotherapy treatments in colorectal cancer.

Among the chemically induced CRC models, the combination of a single dose of azoxymethane (AOM) with three cycles of dextran sodium sulfate (DSS) has proven to shorten the latency time for induction of CRC in rodents. Besides, the tissue injuries quickly reach the aberrant crypt foci-adenoma-carcinoma sequence that occurs in human CRC. The DSS/AOM model has become a prominent model for studying colon carcinogenesis and CRC treatment because of its high reproducibility and potency, as well as the simple and accessible mode of application [9].

\section{Materials}

2.1 Mouse Strains

2.2 Azoxymethane (AOM)(Sigma Aldrich)
Use mouse strains sensitive to carcinogenesis induced by $A O M$ (A/J, SWR/J, FVB/N, C57Bl/6J, BALB/c) provided by most commercial research animal manufacturers. Preferably, use male mice (see Note 1) of 8 weeks of age in all experiments. For animal experimentation, follow FELASA guidelines and approval of the corresponding Ethics Committee for Animal Experimentation.

Dissolve the content of the ampule in $10 \mathrm{~mL}$ of sterilized ultrapure water to make a stock solution of $2.5 \mathrm{mg} / \mathrm{mL}$. Make aliquots and store at $-20^{\circ} \mathrm{C}$. 
2.3 Dextran Sulfate

Sodium Salt (DSS)

Colitis Grade (MP

Biomedicals)

(see Note 2)

\subsection{Additional}

Reagents

\subsection{Equipment}

DSS from MP Biomedicals induces a severe colitis. The sulfur content is approximately $17 \%$ which corresponds to an average of 1.9 sulfate groups per glucosyl residue of the dextran molecule (see Note 2).

1. Animal facility water.

2. Sodium chloride solution $0.9 \%$.

3. $1 \times \operatorname{HBBS}($ Sigma).

4. EDTA 0.5 M (Lonza).

5. DTT (Fisher Scientific).

6. Percoll (Sigma).

7. Collagenase D (Roche).

8. Dispase II (Sigma).

9. DNase (Resuspend at $10 \mathrm{KU} / \mathrm{mL}$ ) (Sigma).

10. Fetal calf serum (FCS).

11. Paraformaldehyde (PFA) $1 \%$.

12. Anti CD8a-FITC (Miltenyi Biotec).

13. AntiF4/80-APC (Miltenyi Biotec).

14. Anti CDl1bFITC-FITC (Miltenyi Biotec).

1. Professional adjustable-volume micropipet $(1000 \mu \mathrm{L})$.

2. Micropipette tips $(1000 \mu \mathrm{L})$.

3. Disposable Syringe $1 \mathrm{~mL}$.

4. Syringe needles gauge $25, \mathrm{~L} 1 / 2$ in.

5. Precision laboratory balance.

6. Digital caliper.

7. Scissors.

8. Forceps.

9. Petri dishes.

10. Round-bottom plate (Nunc, Thermo Fisher Scientific).

11. 40 and $100 \mu \mathrm{m}$ cell strainers (Falcon; BD).

12. 15 and $50 \mathrm{~mL}$ conical centrifuge tubes.

13. Thermal incubator with rotation unit.

14. Cell culture centrifuge.

15. Orbital Shaker. 


\section{Methods}

\subsection{Induction of Colitis-Associated Cancer (CAC)}

1. Separate the cages with the 8 -week-old male mice, which will be used in the experimental and control groups. Mice should be labeled individually with tail tags or ear punching. Two animal groups should be prepared: Control group (receiving isotonic solution and water) and CAC group (receiving AOM and DSS).

2. Prepare a working solution of AOM from the stock solution at $10 \mathrm{mg} / \mathrm{mL}$ stored at $-20^{\circ} \mathrm{C}$. This working solution is dissolved in isotonic saline solution at a concentration of $1 \mathrm{mg} / \mathrm{mL}$.

3. Inoculate mice intraperitoneally (IP) with AOM working solution $(1 \mathrm{mg} / \mathrm{mL})$ at $10 \mathrm{mg} / \mathrm{kg}$ of weight. For the greatest precision in dosing, each animal should be weighed. The weights and doses must be recorded. Calculate injection volume by multiplying animal's weight $(\mathrm{kg}) \times$ dose $(\mathrm{mg} / \mathrm{kg})$ and divide this by the concentration of working solution $(\mathrm{mg} / \mathrm{mL})$. The same volume of isotonic solution is inoculated in the control groups ( see Note 3 ).

4. Prepare $2.5 \%$ DSS solution. Add $100 \mathrm{~mL}$ of animal drinking water to a $1 \mathrm{~L}$ glass beaker. Weigh $25 \mathrm{~g}$ of DSS and transfer to the glass and mix until a clear solution is obtained. Add animal drinking water for a total volume of $1000 \mathrm{~mL}$. Fill the animal water bottle with $100 \mathrm{~mL}$ of $2.5 \%$ DSS solution and place in the corresponding cages. Control mice should get only water. All mice have ad libitum access to drinking water containing $2.5 \%$ DSS or water (control group) for 5 days (see Note 4 ).

5. CAC is induced by intraperitoneal injection of a single dose of the mutagenic agent AOM $(10 \mathrm{mg} / \mathrm{kg})$ on day 0 followed by 3 cycles of $2.5 \%$ DSS in drinking water for 5 days and normal drinking water for 2 weeks (Fig. 1).

\section{Controls}

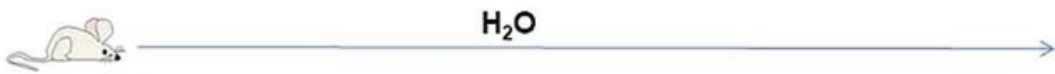

CAC

Sacrifice

Day 56

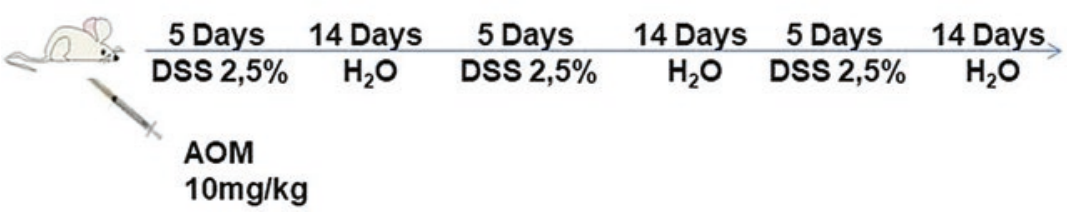

Fig. 1 Protocol for DSS/AOM-induced colitis-associated cancer. Animals receive a single dose intraperitoneally of the mutagenic agent AOM (10 mg/kg) on day 0 followed by 3 cycles of $2.5 \%$ DSS in drinking water for 5 days and normal drinking water for 2 weeks. Control mice only receive water 
Table 1

Assessment of clinical score

\begin{tabular}{ll}
\hline Parameters and score & \\
\hline Weight changes $(\mathrm{g})$ & $<1 \%=0 ; 1-5 \%=1 ; 5-10 \%=2 ; 10-20 \%=3 ;>20 \%=4$ \\
\hline Stool consistency & Normal $=0 ;$ soft feces $=1 ;$ diarrhea $=4$ \\
\hline Visible bleeding & No visible $=0 ;$ visible bleeding $=4$ \\
\hline Mouse behavior & Normal $=0 ;$ slight changes $=1$ abnormal $=4 ;$ immobility $=8$ \\
\hline Dehydration & Normal $=0 ;$ dehydration $=4$ \\
\hline
\end{tabular}

\subsection{Evaluation} of Clinical Score
1. Mice should be weighted and observed daily. Clinical measurements of the disease severity are conducted. The scoring system uses five different parameters to calculate the severity of the disease: weight loss, stool consistency, visible fecal blood, mouse behavior, and dehydration (Table 1). All individual scores are added, resulting in a total clinical score with a maximum of 24 per mouse (see Note 5). An example of disease monitoring employing this clinical score is shown in Fig. 2.

1. On day 56, colorectal tumors can be treated with chemotherapy or immunotherapy protocols. Dose and duration should be adjusted depending on the treatment (see Note 6).

2. On day 56 (or after the corresponding day in case of experimental therapy), euthanize animals in $\mathrm{CO}_{2}$ gas chamber or use any other method in accordance with approved protocol by Ethics Committee for Animal Experimentation.

3. Sterilize with $70 \%$ ethanol solution and carefully make a ventral midline incision in the skin to open the abdominal cavity. Expose the intestine until the cecum is visible. Separate the colon from the small intestine. At this step the difficulty to separate colon from small intestine should be evaluated to measure the degree of adhesion, a parameter of the macroscopic score (Table 2).

4. Cut off the colon just above the cecum and at the end of the rectum.

5. Measure and weight the colon ( see Note 7).

(a) To measure the colon length use a rule or an electronic digital caliber. Put the organ straight but avoid stretching and prevent tissue breakage. Only the colon, excluding the cecum, should be measured. 

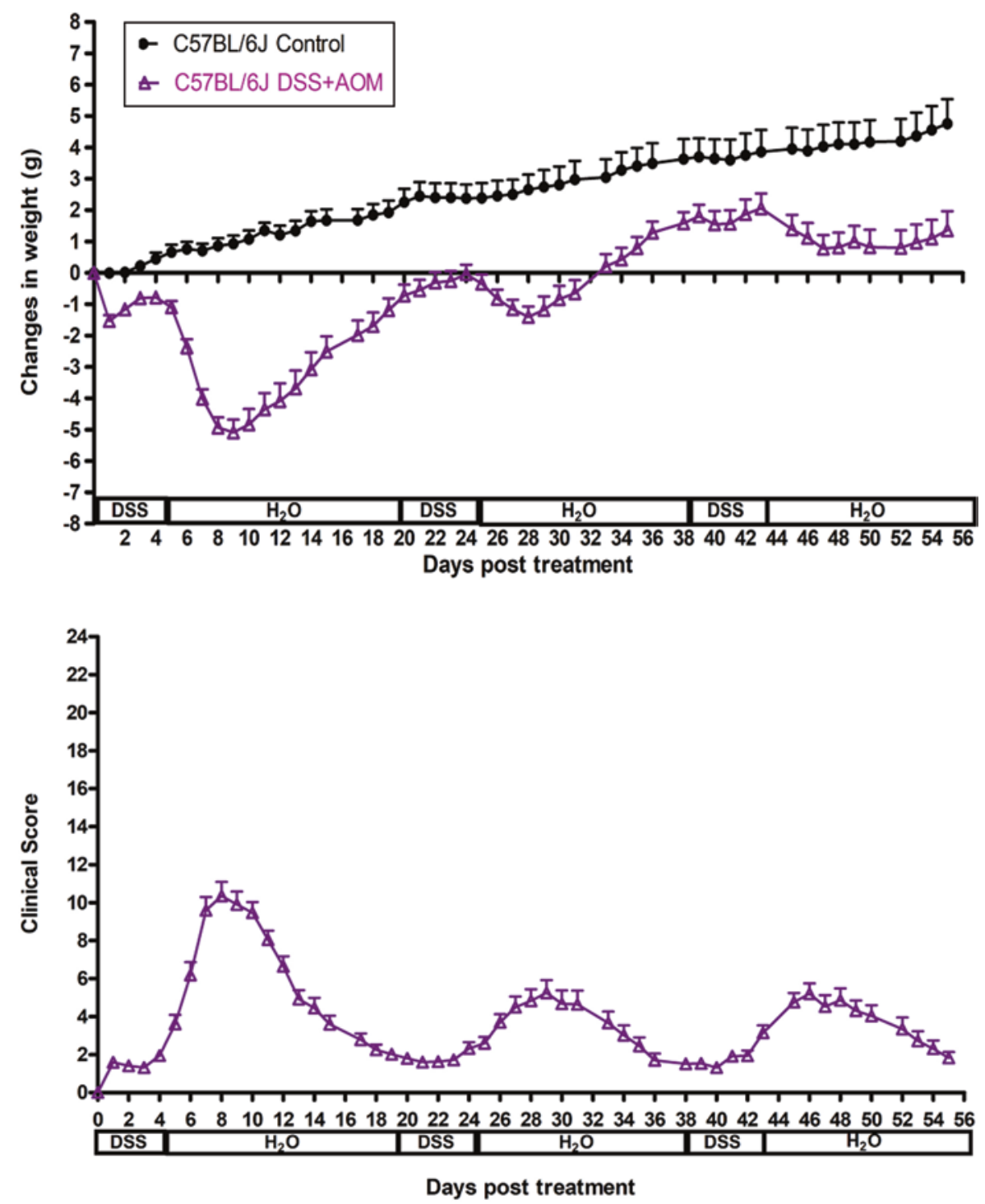

Fig. 2 Representative data of weight loss and clinical score. CAC was induced in male C57BL/6 wild-type (B6) mice following the DSS/AOM protocol. Change in weight was recorded and clinical score was established and evaluated every single day. Control group only received water during the experiment

(b) Separate the cecum and flush the colon to eliminate the feces with $5 \mathrm{~mL}$ of sterile PBS using a syringe with a $21 \mathrm{G}$ needle or a micropipette tip $(1000 \mu \mathrm{L})$. Weight the cleaned colon and score.

6. Carefully open the colon longitudinally and wash again with sterile PBS.

7. Observe and score the visible colonic damage. The scoring system assigns severity scores to six parameters: diarrhea, 
Table 2

Assessment of clinical score

\begin{tabular}{|c|c|}
\hline \multicolumn{2}{|c|}{ Parameters and score } \\
\hline Diarrhea & Normal $=0 ;$ soft $=1 ;$ liquid $=4$ \\
\hline Bleeding & $\mathrm{No}=0 ; \mathrm{Yes}=4$ \\
\hline Erythema & No $=0 ;$ Mild and $/$ or localized $=1 ;$ intense and $/$ or generalized $=2$ \\
\hline Edema & No $=0 ;$ Mild and $/$ or localized $=1 ;$ intense and $/$ or generalized $=2$ \\
\hline Stenosis & No $=0 ; 1$ Stenosis $=1 ; 2$ Stenosis $=2 ;>2$ Stenosis $=3$ \\
\hline Adherences $^{\mathrm{a}}$ & $\begin{array}{l}\text { No adhesions }=0 ; \text { Difficult dissection }=1 ; \text { Visible adhesions }=2 \\
\quad \text { "Wrapped" intestine }=3\end{array}$ \\
\hline
\end{tabular}

${ }^{a}$ Evaluate the adherences during dissection
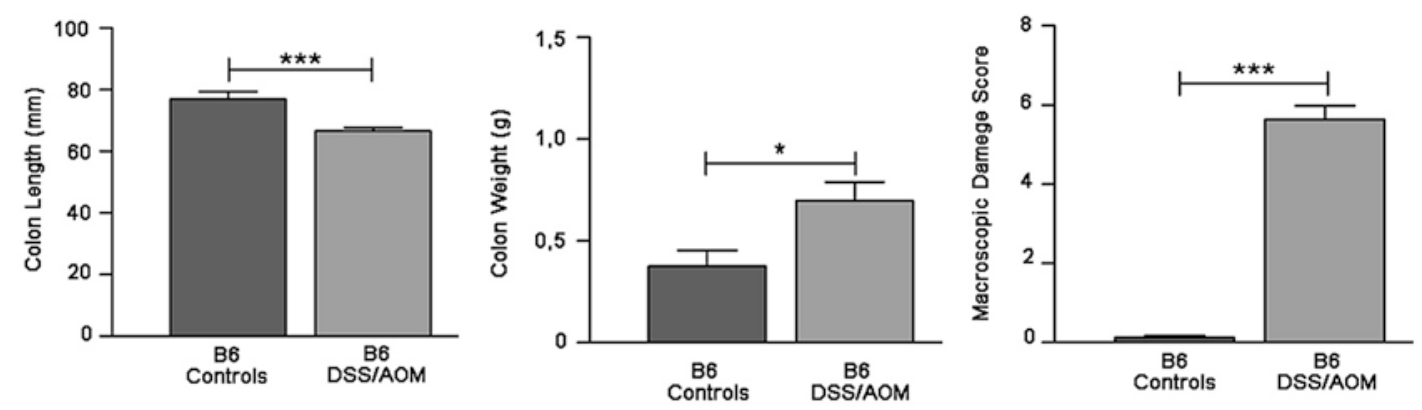

Fig. 3 Representative data of colon length, colon weight, and macroscopic damage in colon. CAC was induced in male C57BL/6 wild-type (B6) mice following the DSS/AOM protocol. Animals were euthanized at day 56 and a macroscopic score was calculated as indicated in Table 2

\subsection{Isolation \\ of Intraepithelial \\ Lymphocytes (IELs) \\ and Lamina Propria \\ (LP) Leukocytes}

bleeding, erythema, edema, stenosis, and adhesions (Table 2). All individual scores are added, resulting in macroscopic damage score. An example of colon length, colon weight, and macroscopic damage evaluation monitoring is shown in Fig. 3.

8. Count the number of macroscopic tumors per mouse in the longitudinally open colon.

9. Measure tumor diameter using a digital caliper. (An example of the tumor appearance is shown in Fig. 4).

10. Calculate the percentage of tumor incidence.

Figure 5 shows the schematic diagram of the protocol to isolate colonic lymphoid cells (LPMCs and IELs).

1. Prepare the predigestion solution by adding $5 \mathrm{mM}$ EDTA and $1 \mathrm{mM}$ DTT to HBSS $(\mathrm{l} \times)(100 \mu \mathrm{L}$ of $0.5 \mathrm{M}$ EDTA and $100 \mu \mathrm{L}$ of $0.1 \mathrm{M}$ DTT for a total volume of $10 \mathrm{~mL}$ HBSS). 


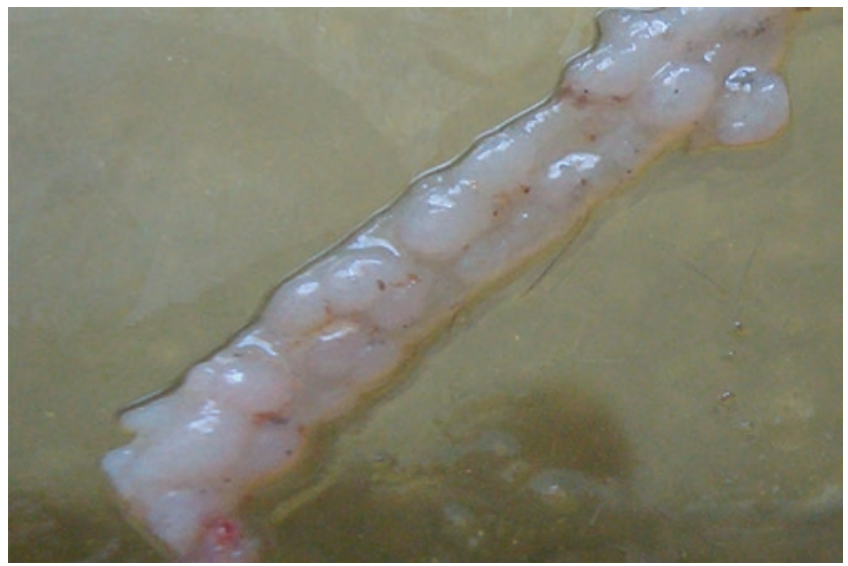

Fig. 4 Representative picture of colon tumors from DSS/AOM-treated B6 wildtype mice at day 56 . Tumors are counted macroscopically and diameter is determined using a digital caliper. CAC was induced in male C57BL/6 wild-type (B6) mice following the DSS/AOM protocol. Animals were euthanized at day 56

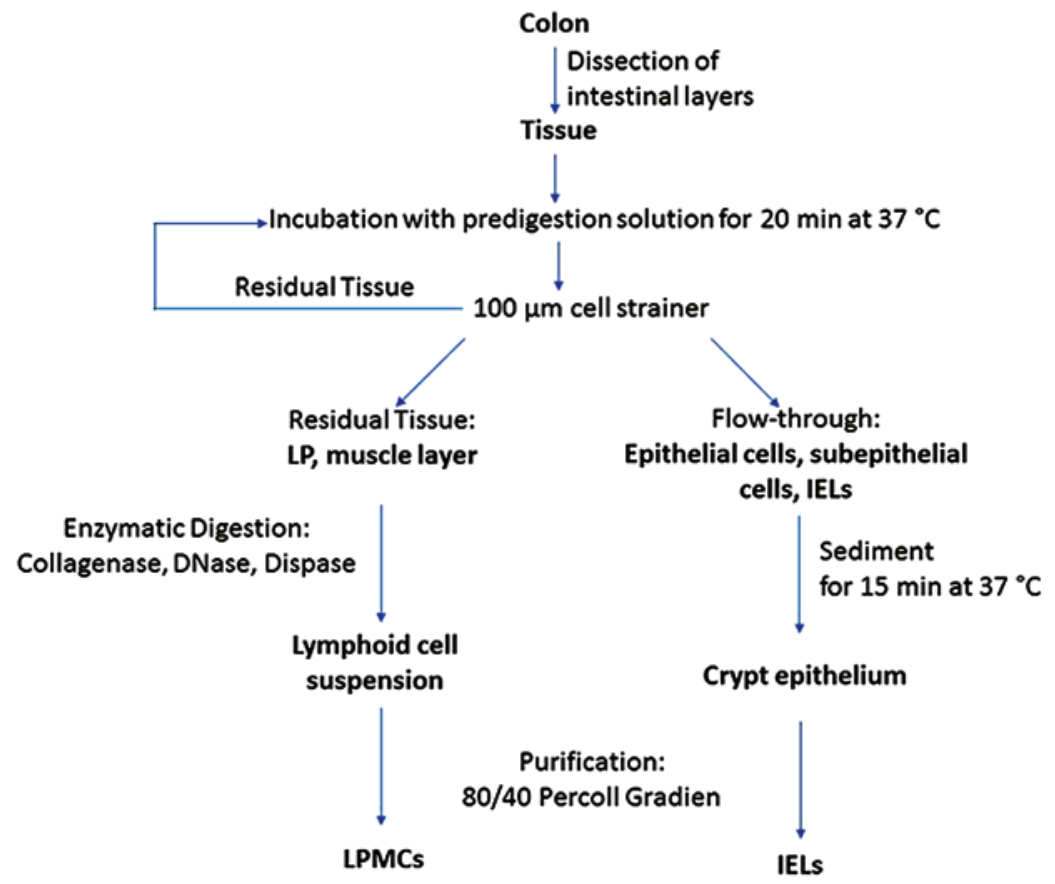

Fig. 5 Schematic summary of the protocol to isolate colonic lymphoid cells (LPMCs and IELS)

2. After evaluating macroscopic damage and tumor development cut the colon into $1-2 \mathrm{~cm}$ pieces with the help of a scalpel or scissors. Place the small pieces in a $50 \mathrm{~mL}$ conical centrifuge tube prefilled with $5 \mathrm{~mL}$ of predigestion solution. Incubate for $20 \mathrm{~min}$ at $37^{\circ} \mathrm{C}$ under slow rotation in an orbital shaker. For a good cell yield, use at least three mice per experimental group. 
3. After incubation, filter the solution containing tissue rests and cells through a $100 \mu \mathrm{m}$ cell strainer. Dissect the residual tissue layers using forceps.

4. Reserve the flow-through that contains the dissected epithelial cells. Store at $4{ }^{\circ} \mathrm{C}$ for the isolation of IELs.

5. Put the pieces retained at the top of the strainer into a $50 \mathrm{~mL}$ conical centrifuge tube prefilled with $5 \mathrm{~mL}$ of fresh predigestion solution. Incubate for $20 \mathrm{~min}$ at $37^{\circ} \mathrm{C}$ under slow rotation in the orbital shaker.

6. While tubes are shaking prepare Digestion solution: dissolve $0.05 \mathrm{~g}$ of collagenase D, $0.05 \mathrm{~g}$ of DNase I, and $0.3 \mathrm{~g}$ of dispase II in $100 \mathrm{~mL}$ of sterile $1 \times$ PBS. Prepare a fresh solution just before using and incubate for a few minutes at $37{ }^{\circ} \mathrm{C}$ (see Note 8).

7. Filter the pieces through a $100 \mu \mathrm{m}$ cell strainer. Using scissors cut the remaining tissue into $1 \mathrm{~mm}$ pieces. Collect the flow-through into the $50 \mathrm{~mL}$ conical centrifuge tube reserved in step 4. Store at $4{ }^{\circ} \mathrm{C}$ for the isolation of IELs.

8. Wash out the remaining EDTA from the tissue pieces by flushing with sterile $1 \times$ PBS through the cell strainer. Collect the tissue into a $50 \mathrm{~mL}$ conical centrifuge tube containing $5 \mathrm{~mL}$ of digestion solution. Incubate the pieces at $37{ }^{\circ} \mathrm{C}$ for $20 \mathrm{~min}$ under slow rotation.

1. For isolation of IELs, allow the cell suspension obtained in steps 4 and 7 to settle for $15 \mathrm{~min}$ at $20^{\circ} \mathrm{C}$. The pellet contains the crypts that can be used for the purification of IELs with Percoll gradient. Centrifuge cells at $500 \times g$ for $10 \mathrm{~min}$ at $20{ }^{\circ} \mathrm{C}$. Discard the supernatant and resuspend the pellet in cold sterile $1 \times$ PBS containing $5 \%$ of FCS.

2. Centrifuge the cells at $500 \times g$ for $10 \mathrm{~min}$ at $20^{\circ} \mathrm{C}$. Discard the supernatant and purify IELs performing a Percoll density gradient (see Subheading 3.4.3).

3.4.2 LPMC Isolation

1. After incubation with digestion solution (step 8), vortex each tube containing cell suspension for $20 \mathrm{~s}$. Pass the remaining pieces through a $40 \mu \mathrm{m}$ cell strainer.

2. Put together all the pieces into a $50 \mathrm{~mL}$ conical centrifuge tube prefilled with $5 \mathrm{~mL}$ of fresh digestion solution. Incubate the pieces at $37^{\circ} \mathrm{C}$ for 20 min under slow rotation.

3 . Repeat steps $\mathbf{1}$ and $\mathbf{2}$ while connective tissue is visible on the strainer (normally 2 to 3 times is enough). The intestine should be now completely digested.

4. Centrifuge the cell suspension at $500 \times g$ for $10 \mathrm{~min}$ at $20{ }^{\circ} \mathrm{C}$. Discard the supernatant and resuspend the pellet in cold sterile $1 \times$ PBS containing $5 \%$ of FCS. 


\subsubsection{Percoll Density} Gradient

\subsection{Surface Protein} Staining for Flow Cytometry
5. Centrifuge the cell suspension at $500 \times g$ for $10 \mathrm{~min}$ at $20^{\circ} \mathrm{C}$. Discard the supernatant and purify LPMCs performing a Percoll density gradient (see Subheading 3.4.3).

1. Prepare $80 \%$ Percoll solution. Mix $8 \mathrm{~mL}$ of Percoll (density: $1124 \mathrm{~g} / \mathrm{mL}$ ) separation solution with $2 \mathrm{~mL}$ of sterile $1 \times$ PBS.

2. Prepare $40 \%$ Percoll solution. Mix $4 \mathrm{~mL}$ of Percoll $(1124 \mathrm{~g} / \mathrm{mL}$ of density) separation solution with $6 \mathrm{~mL}$ of sterile $1 \times$ PBS.

3. Resuspend the pellet (obtained in Subheading 3.4.1, step 2 and/or in Subheading 3.4.2, step 5) in $10 \mathrm{~mL}$ of $40 \%$ Percoll solution. Transfer to a $15 \mathrm{~mL}$ conical centrifuge tube.

4. Using a Pasteur pipette carefully underlay $5 \mathrm{~mL}$ of $80 \%$ Percoll solution.

5. Centrifuge the $40 / 80$ Percoll gradient at $1000 \times g$ for $20 \mathrm{~min}$ at $20{ }^{\circ} \mathrm{C}$ without brake. The LPMCs and IELs should be visible in a white ring at the interphase of the two different Percoll solutions. Erythrocytes should be visible in a red ring below the white ring. At the top is the layer of epithelial cells and at the bottom a pellet containing debris and dead cells.

6. Using a pasteur pipette, aspirate most of the cells of the white ring without disturbing the interface. Add to $15 \mathrm{~mL}$ tube and wash once with $1 \times$ PBS.

7. Centrifuge the cell suspension at $500 \times g$ for $10 \mathrm{~min}$ at $20{ }^{\circ} \mathrm{C}$. Discard the supernatant and resuspend the pellet in sterile $1 \times$ PBS containing $5 \%$ of FCS ( see Note 9 ).

1. Determine cell number. Adjust the concentration to $5 \times 10^{6}$ cells $/ \mathrm{mL}$. Plate $5 \times 10^{5}$ cells $(100 \mu \mathrm{L}$ of cell suspension $)$ into a 96-well round-bottom plate.

2. Centrifuge at $500 \times g$ for $5 \mathrm{~min}$ at $4{ }^{\circ} \mathrm{C}$. Decant supernatant by inverting the plate.

3. Resuspend cells in $50 \mu \mathrm{L}$ of PBS supplemented with $5 \%$ fetal calf serum (PBS 5\% FCS) containing rat anti-Mouse CDl6/ CD32 mAb (Clone 2.4G2; Table 3) to prevent FcR unspecific binding.

4. Resuspend cells in $100 \mu \mathrm{L}$ of PBS supplemented with $5 \%$ fetal calf serum (PBS 5\% FCS) containing the antibodies against the markers indicated in Table 3.

5. Incubate for $10 \mathrm{~min}$ in the dark at $2-8{ }^{\circ} \mathrm{C}$.

6. Centrifuge at $500 \times g$ for $5 \mathrm{~min}$ at $4{ }^{\circ} \mathrm{C}$. Decant supernatant by inverting the plate.

7. Wash cells with $200 \mu \mathrm{L}$ of PBS 5\% FCS.

8. Centrifuge at $500 \times g$ for $5 \mathrm{~min}$ at $4{ }^{\circ} \mathrm{C}$. Decant supernatant by inverting the plate. 


\section{Table 3}

Examples of antibodies used for analysis of IELs and LPMC by flow cytometry

\begin{tabular}{|c|c|c|}
\hline Cell type & Antibodies & Expected signal \\
\hline \multirow[t]{4}{*}{ CD8+ (ab) T Cells } & CD45, FITC & $(+)$ \\
\hline & CD8a, Alexa 405 & $(+)$ \\
\hline & TCRab, PE & $(+)$ \\
\hline & $\mathrm{CD} 3, \mathrm{APC}$ & $(+)$ \\
\hline \multirow[t]{4}{*}{ CD8+ (gd) T Cells } & CD45, FITC & $(+)$ \\
\hline & CD8a, Alexa 405 & $(+)$ \\
\hline & TCRgd, PE & $(+)$ \\
\hline & $\mathrm{CD} 3, \mathrm{APC}$ & $(+)$ \\
\hline \multirow{4}{*}{ CD4+ T Cells } & CD45, FITC & $(+)$ \\
\hline & $\mathrm{CD} 4, \mathrm{PE}$ & $(+)$ \\
\hline & TCRab, PE & $(+)$ \\
\hline & $\mathrm{CD} 3, \mathrm{APC}$ & $(+)$ \\
\hline \multirow[t]{4}{*}{ Macrophages } & CD45, FITC & $(+)$ \\
\hline & CD1lb, Alexa 405 & $(+)$ \\
\hline & CDIlc, PE & $(+)(-)^{\mathrm{a}}$ \\
\hline & $\mathrm{F} 4 / 80, \mathrm{APC}$ & $(+)$ \\
\hline \multirow[t]{4}{*}{ Neutrophils } & CD45, FITC & $(+)$ \\
\hline & CD11b, Alexa 405 & $(+)$ \\
\hline & CDIlc, PE & $()$, \\
\hline & Ly6G, APC & $(+)$ \\
\hline \multirow[t]{4}{*}{ NK cells } & CD45, FITC & $(+)$ \\
\hline & NKp46, Alexa 405 & $(+)$ \\
\hline & $\begin{array}{l}\text { NKl.1, PE } \\
\text { CD49b, PE }\end{array}$ & $(+)^{c}$ \\
\hline & RORgt, APC & $(-)$ \\
\hline \multirow[t]{5}{*}{ DC } & CD45, FITC & $(+)$ \\
\hline & CDIlb, Alexa 405 & $(+)(-)^{\mathrm{a}}$ \\
\hline & CDllc, PE & $(+)$ \\
\hline & $\mathrm{F} 4 / 80, \mathrm{APC}$ & $(-)$ \\
\hline & CD103, APC.Cy7 & $(+)$ \\
\hline
\end{tabular}


Table 3

(continued)

\begin{tabular}{lll}
\hline Cell type & Antibodies & Expected signal \\
\hline Eosinophils & CD45, FITC & $(+)$ \\
& CD11b, Alexa 405 & $(+)$ \\
Siglec-F, PE & $(+)$ \\
& Ly6G, APC & $(+/-)^{\mathrm{b}}$ \\
\hline
\end{tabular}

Concentration of $\mathrm{Ab}$ used for the staining is indicated by the manufacturers. The fluorophore is indicated as a reference and other similar dyes can be used

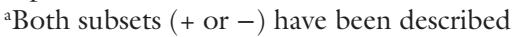

${ }^{b}$ Eosinophils express intermediate levels of Ly6G in colitic mice

'NKl.1 is only expressed in $\mathrm{C} 57 \mathrm{Bl} / 6$ mouse strains

9. Resuspend cells in $100 \mu \mathrm{L}$ of $1 \%$ Paraformaldehyde (PFA) to fix the cells. Incubate for $1 \mathrm{~h}$ in the dark at $4{ }^{\circ} \mathrm{C}$.

10. Centrifuge at $500 \times g$ for $5 \mathrm{~min}$ at $4^{\circ} \mathrm{C}$. Decant supernatant by inverting the plate.

11. Resuspend cell pellet in a suitable amount of PBS for analysis by flow cytometry.

\section{Notes}

1. Both males and females develop DSS/AOM colitis-associated cancer, but males develop more reproducible and aggressive disease than females.

2. Dextran sulfate is a polyanionic derivative of dextran produced by esterification of Dextran with chlorosulfonic acid. The sulfur content is approximately $17 \%$ which corresponds to an average of 1.9 sulfate groups per glucosyl residue of the dextran molecule. DSS from MP Biomedicals induces a severe colitis as indicated by different parameters including body weight loss, colon weight/length, Disease Activity Index, and histological scores. This DSS is well characterized and as indicated by the manufacturer presents several advantages.
(a) Highest sulfur content: 19\%.
(b) Highest chirality: $+104^{\circ}$ of specific rotation.
(c) Lowest pH: 6.2 at $1 \%$ solution.

3. Example of dosage calculation
(a) Mouse: $30 \mathrm{~g}$ body weight $(0.030 \mathrm{~kg})$.
(b) Required dose of AOM: $10 \mathrm{mg} / \mathrm{kg}$.
(c) Concentration of AOM working solution: $1 \mathrm{mg} / \mathrm{mL}$. 
(d) Needed dose: $0.030 \mathrm{~kg} \times 10 \mathrm{mg} / \mathrm{kg}=0.30 \mathrm{mg}$.

(e) Needed volume: $0.30 \mathrm{mg} / \mathrm{l} \mathrm{mg} / \mathrm{mL}=0.30 \mathrm{~mL}=\mathbf{3 0 0} \mu \mathrm{L}$.

- Summarizing: A working solution at $1 \mathrm{mg} / \mathrm{mL}$ facilitates the dosage of the AOM. In this way the mice's body weight, in grams, multiplied per 10 is the volume to be administered, in $\mu \mathrm{L}$.

(f) Inoculated AOM volume $(\mu \mathrm{L})=$ body weight $(\mathrm{g}) \times 10$.

4. In generally, DSS is used in a range of dose between 1.5 and $3 \%$. The reproducible induction of colitis depends on many factors that may influence its inflammatory potential, like genetic background of the animals, age, gender, animal health conditions and the institutional animal facility environmental factors, as well as DSS characteristics (manufacturer, number of lots, sulfur content, molecular weight), concentration and treatment duration. Summarizing, it is necessary to determinate the optimal DSS dose required. Normally, $120-150 \mathrm{~mL}$ of $2.5 \%$ DSS solution is enough for five mice and for a cycle ( 5 days) but is necessary to check DSS consumption in each group to ensure a correct treatment. While DSS is quite stable at room temperature, treatment should be changed if any growth (turbidity) appears.

5. DSS administration induces clinical signs rapidly. These symptoms worsen dramatically, increasing clinical score and mortality, particularly in the first recovery phase (days 8-12). Mice show weight loss, diarrhea, rectal bleeding, and piloerection. In more serious cases, mice will exhibit hunched back, symptoms of dehydration, and reduced mobility.

6. For example, immunotherapy employing antibodies or soluble receptors against inflammatory cytokines, like $\mathrm{TNF} \alpha$, have been shown to reduce the incidence of CAC in mice at a dose of $3 \mathrm{mg} / \mathrm{kg}$ [10].

7. The length of the colon decreases as colitis develops, which is a quantitative measure of disease severity. At the same time, the colonic wet weight increases in chronic gut inflammation, being another parameter to quantify $[11,12]$.

8. The amount of DNase I must be enough to digest DNA and avoid sample viscosity. If the cell suspension clumps together, increase the amount of DNase I [13].

9. Purified LPMCs and IELs can be used in flow cytometry analysis (extracellular markers, cytotoxic molecules, and cytokines), cultured to quantify cytokines in supernatants or used to analyze cytotoxicity against tumor cells. Furthermore, cells can be used for proliferation assays, isolation of mRNA to perform PCR or protein isolation for western blot or ELISA experiments. 


\section{Acknowledgments}

This work was supported by Fondo Social Europeo (FSE), grant SAF2014-54763-C2-1-R from Spanish Ministry of Economy and Competitiveness and grant AEI-010500-2015-161 from the Spanish Ministry of Industry, Energy and Tourism. MA and LS were supported by a PhD fellowship from University of Zaragoza/ Santander Bank Foundatio and FPI from Spanish Ministry of Economy and Competitiveness (LS). JP was supported by ARAID Foundation.

\section{References}

1. Haggar FA, Boushey RP (2009) Colorectal cancer epidemiology: incidence, mortality, survival, and risk factors. Clin Colon Rectal Surg 22(4):191-197. https://doi.org/10.10 $55 / \mathrm{s}-0029-1242458$

2. Asano TK, McLeod RS (2004) Nonsteroidal anti-inflammatory drugs and aspirin for the prevention of colorectal adenomas and cancer: a systematic review. Dis Colon Rectum 47(5):665-673. https://doi.org/10.1007/ sl0350-003-0111-9

3. Keerthivasan S, Aghajani K, Dose M, Molinero L, Khan MW, Venkateswaran V, Weber C, Emmanuel AO, Sun T, Bentrem DJ, Mulcahy M, Keshavarzian A, Ramos EM, Blatner N, Khazaie K, Gounari F (2014) beta-Catenin promotes colitis and colon cancer through imprinting of proinflammatory properties in $\mathrm{T}$ cells. Sci Transl Med 6(225):225-228. https:// doi.org/10.1126/scitranslmed.3007607

4. Terzic J, Grivennikov S, Karin E, Karin M (2010) Inflammation and colon cancer. Gastroenterology 138(6):2101-2114.e5. https://doi.org/ $10.1053 /$ j.gastro.2010.01.058

5. Wang D, Wang H, Shi Q, Katkuri S, Walhi W, Desvergne B, Das SK, Dey SK, DuBois RN (2004) Prostaglandin E(2) promotes colorectal adenoma growth via transactivation of the nuclear peroxisome proliferator-activated receptor delta. Cancer Cell 6(3):285-295. https://doi.org/10.1016/j.ccr.2004.08.011

6. O'Brien CA, Pollett A, Gallinger S, Dick JE (2007) A human colon cancer cell capable of initiating tumour growth in immunodeficient mice. Nature 445(7123):106-110. https:// doi.org/10.1038/nature05372

7. Ricci-Vitiani L, Lombardi DG, Pilozzi E, Biffoni $M$, Todaro $M$, Peschle C, De Maria R (2007) Identification and expansion of human colon-cancer-initiating cells. Nature 445(7123):111-115. https:// doi.org/10.1038/nature05384

8. De Robertis M, Massi E, Poeta ML, Carotti S, Morini S, Cecchetelli L, Signori E, Fazio VM (2011) The AOM/DSS murine model for the study of colon carcinogenesis: From pathways to diagnosis and therapy studies. J Carcinog 10:9. https://doi.org/10.4103/1477-3163.78279

9. Rosenberg DW, Giardina C, Tanaka T (2009) Mouse models for the study of colon carcinogenesis. Carcinogenesis 30(2):183-196. https://doi.org/10.1093/carcin/bgn267

10. Popivanova BK, Kitamura K, Wu Y, Kondo T, Kagaya T, Kaneko S, Oshima M, Fujii C, Mukaida N (2008) Blocking TNF-alpha in mice reduces colorectal carcinogenesis associated with chronic colitis. J Clin Invest 118(2):560-570. https://doi.org/10.1172/ JCI32453

11. Chassaing B, Aitken JD, Malleshappa M, Vijay-Kumar M (2014) Dextran sulfate sodium (DSS)-induced colitis in mice. In: Current protocols in immunology. John EC, et al. (Ed.). 104:Unit 15 25. https://doi. org/10.1002/0471142735.iml525s104

12. Muller S, Lory J, Corazza N, Griffiths GM, Z'Graggen K, Mazzucchelli L, Kappeler A, Mueller C (1998) Activated CD4+ and CD8+ cytotoxic cells are present in increased numbers in the intestinal mucosa from patients with active inflammatory bowel disease. Am J Pathol 152(1):261-268

13. Weigmann B, Tubbe I, Seidel D, Nicolaev A, Becker C, Neurath MF (2007) Isolation and subsequent analysis of murine lamina propria mononuclear cells from colonic tissue. Nat Protoc 2(10):2307-2311. https://doi. org/10.1038/nprot.2007.315 